\title{
Incidence of Fungi Aspergillus Section Nigri in Different Varieties of Grapes
}

\author{
Michelle Terra (I), Nathasha De Asevedo Lira (I), Wilder Santiago \\ (I), Maria Das Graças Cardoso (I), Giuliano Elias Pereira (II), \\ Guilherme Prado (III), Luís Roberto Batista (I)
}

(I) UFLA - UNIVERSIDADE FEDERAL DE LAVRAS (CAMPUS DA UFLA, CEP 37200-000, CAIXAPOSTA 3037), (II) EMBRAPA - EMBRAPA UVA E VINHO/SEMIÁRIODO (Rodovia BR 428, Km 152, CP 23), (III) FUNED - FUNDAÇÃO EZEQUIEL DIAS (R. Conde Pereira Carneiro, 80 - Gameleira, Belo Horizonte - MG, 30510-010)

\section{Resumo}

The Aspergillus Section Nigri have been considered as the main fungi responsible for the infection of varieties grapes with ochratoxin A (OTA), can be isolated from the early stages of berry development until the period of harvest. OTA is a secondary metabolite produced by some species of filamentous fungi especially Aspergillus and Penicillium. It is a mycotoxin classified as a possible human carcinogen (group 2B) by the International Agency for Research on Cancer (IARC). Among the Aspergillus Section Nigri, the species Aspergillus carbonarius is considered the main source of OTA in grapes, and the toxin levels vary depending on the type of wine and different grapevine growing regions. This study aimed to evaluate the incidence of Aspergillus section Nigri in wine grapes of different cultivars of tropical northeast region of Brazil, with special attention to potential OTA producing species. In this region five varieties of grapes, totaling 15 samples. The species of Aspergillus Section Nigri were identified by morphological characteristics. Measuring the production of ochratoxin A by fungi was performed by Liquid Chromatography with fluorescence detection. A total of 272 Aspergillus Section Nigri, identified in the species A. carbonarius, A. niger, A. niger Aggregate, A. foetidus, A. japonicus and A. aculeatus were isolated. The fungi most frequently detected in grapes were Group A. niger Aggregate (42\%), followed by the species A. 
carbonarius (38\%). The Petit Verdot grape was presented the highest incidence of Aspergillus Section Nigri, especially of A. carbonarius. All isolates of A. carbonarius (103) were OTA producers in average levels (5$20 \mathrm{mg}$ OTA / g CYA) and high (> $20 \mathrm{mg}$ OTA / g CYA), while none of the other species were isolated ochratoxigenics. The results showed that the type of grape cultivar may influence the incidence of Aspergillus Section Nigri. Moreover, for the region, the potential risk of contamination of grapes with OTA associated with A. carbonarius, due to the high frequency of occurrence and the levels produced in vitro. The presence of toxigenic species in the samples do not necessarily indicate a risk of contamination of OTA in wines of the region, but the importance of monitoring particularly during the harvest.

Palavras-Chave: ochratoxin, Aspergillus, wine, mycotoxins Agência de Fomento: FAPEMIG, CNPq 